\title{
Leprosy - the source of infection and its mode of transmission
}

\author{
CK JOB
}

National Hansen's Disease Center, Carville, LA 70721, U.S.A.

Leprosy is a communicable disease caused by Mycobacterium leprae. Two principal factors involved in the transmission of the disease are the source of infection and the mode of entry. Although a lot is known about the source of $M$. leprae, the mode of transmission, till date, is shrouded in mystery. In this paper, I shall attempt to present to you a review of the relevant literature on the subject and add some of my own observations.

Source of infection

Until recently man was the only known source of infection. With the accumulating evidences showing feral armadillos harboring a disease caused by an acid-fast organism indistinguishable from M. leprae using all the now known tests for identification (1), it can no longer be said that man is the only source of infection. Recently, some cultivable and noncultivable acid-fast organisms from sphagnum and moss vegatation in coastal Norway and other parts of the European continent have been isolated (2). The results on studies to identify these organisms are awaited with great interest.

In a recent paper it has been said that the role of armadillos in the transmission of $M$. leprae to man is negligible (3). It is important to further investigate the armadillo as a natural reservoir of M. leprae.

Leprosy patients can be broadly divided into two groups - those who are bacilliferous to such an extent that organisms overflow from them into the environment and those who have a small number of bacilli limited to the intracellular locations and ordinarily have no means of exit from the body. The patients of the lepromatous and borderline lepromatous spectrum belong to the former and those who are classified as tuberculoid, borderline tuberculoid, indeterminate and purely neural come under the latter group. The patients of the lepromatous spectrum discharge $M$. leprae into the surrounding environment through nasal secretions, saliva, exudate from ulcers on the lepromatous skin, and normal secretions of the sweat, sebaceous and mammary glands.

The importance of nasal lesions and their role in the 
dissemination of $M$. leprae has been reported as early as 1930 (4). According to Cochrane "a person with positive nasal secretion is relatively more infective than one in whom bacilli are found in the deeper parts of the corium of the skin" (5). The nose as a source of dissemination of $M$. leprae was rediscovered in the recent past and its importance reemphasized, perhaps, rightly so, by many workers. Pedley demonstrated the fact that a large number of acidfast bacilli escape through the nasal secretions of lepromatous patients $(6,7)$. His reports were followed by that of Davey and Rees who showed severe nasal involvement in 53\% of 295 patients in early lepromatous leprosy. They quantified the organisms in the nasal discharge and stated that $2.4 \times 10^{8}$ bacilli escape daily from the nose of lepromatous patients (8). The histopathological appearance of lepromatous lesions of the nose was well documented as early as 1966 by Job et al. (9) and recently by Barton et al. in 1973 (10).

Lepromatous granuloma was known to involve the mouth, pharynx and larynx as well (11). Lesions have been demonstrated in the lips, gums, teeth, tongue, oral mucosa, and hard and soft palate. Recently, discharge of a large number of bacilli in saliya has been identified and quantified. It is reported that $1.6 \times 10^{6} \mathrm{M}$. leprae can be isolated per mouth wash (12).

In a histopathological study of the skin lesions in leprosy acid-fast bacilli were demonstrated in sweat glands, sebaceous glands, hair follicles, epithelial cells and keratin (13). There is an earlier report of the presence of $M$. leprae in the epidermis (14). M. leprae is constantly discharged through unbroken skin of bacilliferous lepromatous patients along with normal secretions of the glands and through keratin.

I believe that the mode of escape of the organisms from skin and nasal mucosa is similar and that the bacilli usually come out in small numbers if the epithelium is unbroken, along with the normal secretions of the subepithelial glands. When ulcerated, equally large numbers of $M$. leprae escape from the nose and skin. However, the lining epithelium of the mucous membrane of the nose is much thinner and more delicate and therefore given the same subepithelial nodular infiltration of lepromatous granuloma, the nasal mucous membrane ulcerates far more easily than the skin. Pedley has shown that human milk from lepromatous patients may also contain M. leprae and 4 ounces of milk may have up. to 2 million bacilli (15).

A question often raised is whether non-lepromatous patients discharge bacilli into the surrounding environment or not. The lesions in this group of patients are usually in the skin and peripheral nerves and rarely in the mucous membrane. In almost all of them, the skin smears are negative for acid-fast bacilli using routine methods of examination, except during the reactive phase when ulceration of the skin lesion may occur. Nerve abscesses are known to produce sinuses, discharging caseous material containing bacilli. Histologically bacilli are seen in arrector pili muscles, Schwann cells, perineurial cells and very rarely macrophages. During the reactive phase, there is evidence of bacillary multiplication and 
fairly large numbers of acid-fast bacilli are seen inside macrophages. It has been reported that in Nauru where $90 \%$ of the patients are maculo anesthetic $30 \%$ of the population have the disease (16). Brown, from his experience, states that most patients at sometime or other may be infectious (17). As one who studies the histomorphology of leprosy lesions, I see no reason to contribute to the view that nonlepromatous patients in general are infectious. However, I will admit that some of them may become infectious during the reactive phase when lesions show evidence of ulceration or sinus formation. The finding of so-called disproportionate prevalence of the disease in one endemic area where a large majority are of the tuberculoid spectrum, can be explained by other means. It should also be mentioned here that, to my knowledge, none has isolated enough organisms from nonlepromatous patients to infect the available animal models, even the most susceptible ones. Therefore, I would conclude that the role of nonlepromatous patients as a source of infection is comparatively very small indeed.

Are there carriers of M. leprae? If so, where do they carry the organisms? In a study of 7500 normal people in an endemic area by Chatterjee in 1976, 5000 skin biopsies were examined for M. leprae using the concentration technique (18). No histopathological examination was done. Acid-fast bacilli were isolated from $5.8 \%$ of the specimens studied. These organisms were noncultivable and their numbers were not large enough to grow in the mouse footpads. Similar findings were reported earlier by Figueredo and Desai in 1950 (19). It is not known whether these organisms are truly $\mathrm{M}$. leprae and also in what part of the skin they remain. If these normal individuals carry viable M. leprae on their skin, they are possibly infectious and can be considered as carriers. In this connection it must be pointed out that there is a group of undiagnosed early asymptomatic lepromatous patients who carry a large number of bacilli in their skin and mucous membrane and are capable of disseminating M. leprae.

Finally, are patients under treatment infectious? The only method now available to test the viability of $\mathrm{M}$. leprae is the mouse footpad culture. It has been shown that if the morphological index of a patient is 0 , that is, if solid-staining bacilli are absent, the organisms fail to multiply in mouse footpads (20). It has also been shown that if a patient has had D.D.S. therapy for over 3 months, the organisms isolated from him are no more solid and are not cultivable in the footpads of mice (21). The conclusion drawn that non-solid-staining bacilli are nonviable and therefore noninfectious, is not accepted universally (22).

Retrospective studies show that infectivity of lepromatous patients on D.D.S. therapy is much reduced long before they become bacteriologically negative $(23,24)$. Lepromatous ulcers of the nose and skin heal quickly during antileprosy treatment as a result of lowered bacterial load and reduced edema of the lesions. Therefore, the overflow of the organisms into the environment from these patients is only through normal secretions which is much less. If 
it is agreed that a significantly large number of organisms, if not all, in a treated patient is dead, the role of patients under treatment, in spreading the infection is negligible.

Mode of transmission

Pathogenic organisms enter the body generally along 3 routes, namely the skin, the gastrointestinal tract, and the respiratory passage. The establishment of the infection will depend on the virulence of the organism and the susceptibility of the individual. Virulence has 2 facets, namely the infectivity and the pathogenicity. Infectivity is the ability of the organism to get a foothold on the host and multiply there. Pathogenicity is its power to produce pathological changes and cause disease by altering the tissue components and interfering with their normal function. The susceptibility of the individual will depend on his constitution, environment, and immune mechanism. Each of these is a broad subject and I do not intend to dwell on any one of them. I will only review the findings that are relevant to the mode of transmission of $M$. leprae.

It was once thought that $M$. leprae which is not cultivable in laboratory media or tissue cultures, cannot survive for any length of time outside the human body and that intimate contact facilitates the organism discharged from the patient to be directly transmitted to the contact for the infection to take place. It is now known that $M$. leprae can remain alive in dried nasal secretions up to 7 days (8) and in moist soil at room temperature for 46 days (12). These findings are of great interest and bring a different dimension to the understanding of the mode of transmission. It is important to study further the survival of $M$. leprae in different environments.

M. leprae was thought to be only mildly infectious. The study of Godal et al. in 1976 has indicated that infectivity of M. leprae is very high. About 50\% of the subjects with occupational or household exposure to $M$. leprae for more than 1 year gave a positive immune response to $\mathrm{M}$. leprae using lymphoblast transformation test (25). However, it has been reported that only $5.8 \%$ of close contacts as between spouses develop the disease (26). Therefore, it is clear that although the infectivity of $M$. leprae is high, the pathogenicity is very low.

Transmission of leprosy can be both direct and indirect. In a study the attack rate is 4 times more in contacts than in noncontacts (24). In another study the attack rate among household contacts is 10 times higher than from the general population. This rate is doubled if there are multiple index patients in the same household (28). It is reasonable to accept that direct contact is perhaps far more effective in conveying the disease than indirect contact. Organisms may be carried live in clothes, objects used by the patient, food, water, dust, etc. The floor of the house or hospital or the ground where the infected material is shed, all 
contain live bacilli. It must be conceded that indirect method of transport of bacilli is another important factor in the transmission of the disease.

Some workers have suggested that the blood sucking insects like fleas, bed bugs, lice, and mosquitoes can carry M. leprae $(29,30)$. Acid-fast bacilli isolated from mosquitoes have been identified as M. leprae using mouse footpad culture (31). Usually pathogens carried by vectors go through a cycle to become infectious as in plasmodium or they live and multiply in vectors, like rickettsia or viruses. Recently, Geater has reported the housefly as a vehicle for M. leprae (32). The housefly serves as a transport for many pathogens in the tropics. M. Jeprae can be conceived as one of its rare, and not quite so important passengers. The role of vectors in transferring $M$. leprae mechanically should be very small indeed.

What is the mode of entry of $M$. leprae into the body? Let me begin by saying the exact site and mode of entry is not yet defined. There are several hypotheses.

The age-old concept of making skin the favored site of entry has had its ups and downs. Several authors have identified M. leprae in the skin of contacts and it is also reported a higher percentage among those positive contacts develop leprosy $(18,19)$. Assuming that these organisms survive on their skin surface, they should have been transferred from the patients by direct contact, from fomites or by other mechanical means.

M. leprae is an enert organism, is nonmotile and is not known to produce any toxins. Therefore, it could not possibly penetrate the unbroken skin and the only way it gains access into the skin is through broken epithelium caused by minor injuries, insect bites or scabetic lesions. In a large majority of persons thus infected, the organisms could easily be taken up by macrophages and are destroyed by nonspecific and specific immune mechanisms. In a study it was found that $M$. leprae is ingested by macrophages within 20 minutes (33). In some individuals $M$. leprae may be engulfed by parenchymatous cells such as endothelial cells, arrectores pili muscles, or perineurial cells. Thus, much unlike other pathogens, M. leprae may get an unorthodox, unconventional entry into the body, and remain unrecognized or though unrecognized unharmed by the immune system. It is quite possible that this is the beginning of an indeterminate lesion, the primary lesion in leprosy.

It is known that the initial lesion is single and shows a regional variation influenced by socioeconimic factors and the secondary lesions are multiple and are in the peripheral parts of the body, being the preferential site of M. leprae (34). Further, there are patients who have a single nodular lepromatous lesion with no signs of the disease in any other parts of the body $(35,36)$. Certainly the skin entry of $\mathrm{u}$. leprae is favored by many workers.

Recently a strong case is being put forward in favor of the infection through the respiratory tract (37). Rees has successfully infected T.900r mice by exposing their heads to an aerosol containing M. leprae (38). M. leprae is also isolated from the 
lungs several months after the infection, although histopathological lesions in the lungs are not shown. It is quite possible lung tissue can serve as a transit point of $M$. leprae especially the alveolar macrophages. In a study by Chacko (39) of nasal biopsies of contacts, lesions suggestive of indeterminate leprosy have been demonstrated. However, it is felt that the epidemiological evidence is not suggestive of an airborne infection (34).

Pedley has pointed out that a breast fed infant of a lepromatous mother can ingest millions of bacilli in a day and has suggested that the gastrointestinal tract is a mode of entry of M. leprae. The transport of $M$. leprae by flies can easily carry them through contaminated food into the intestinal tract. As in tuberculosis, intestinal mucosa, without showing any pathological lesions can serve as an entry point of $M$. leprae. In an autopsy study, $M$. leprae was conspicuous by its absence in mesenteric glands $(\overline{40})$. Certainly further studies are indicated to validate these hypotheses.

In this connection, I am reminded of the story of a few blind men who went to see an elephant. One felt the trunk and said "Elephant is like a snake," another felt its legs and exclaimed "Elephant is like a pillar, "yet another felt the tusk and thought "Elephant is like a spear," and so on. Unfortunately, none of them saw the elephant. This may summarize our present position with regard to the mode of transmission of $M$. leprae.

There is much more ground to be covered with regard to this subject, and I hope in the not too distant future we will be in a better position to define the mode of entry of $M$. leprae and thus be able to suggest measures to prevent its entry.

\section{References}

1 Walsh GP, Storrs EE, Burchfield HP, Cottrell LH, Vidrine MF, Binford $\mathrm{CH}$. Leprosy-like disease occurring naturally in armadillos. J Reticuloendothelial Soc, 1975, 18, 347-351.

$2 \mathrm{Kazda} \mathrm{J}$, Lorenz MI, Muller K. Isolation of noncultivable acidfast bacilli in sphagnum and moss vegetation by footpad technique in mice. Int $\mathrm{J}$ Lepr, 1980, 48, 1-5.

3 Filice GA, Greenberg RN, Fraser DW. Lack of observed association between armadillo contact and leprosy in human. Am J Trop Med Hyg, 1977, 26, 137-139.

4 Klingmuller G. Die Leprae, as quoted by Davey TF, Barton R.PE. In Dharmendra, ed. Leprosy 1. Bombay: Kothari Medical Publishing House, 1930, 223.

5 Cochrane RG. Lesions of the nose, throat, and ears. In Cochrane RG, Davey TF, eds. Leprosy in Theory and Practice. Bristol: John Wright, 1964.

6 Pedley JC. Composite skin contact smears, method of demonstrating the nonemergence of $\mathrm{M}$. leprae from intact lepromatous skin. Lepr Rev, 1970, 41, 31-43. 
7 Pedley JC. The nasal mucus in leprosy. Lepr Rev, 1973, 44, 3335 .

8 Davey TF, Rees RJW. The nasal discharge in leprosy, clinical and bacteriological aspects. Lepr Rev, 1974, 45, 121-134.

9 Job CK, Karat ABA, Karat S. The histopathological appearance of leprous rhinitis and pathogenesis of septal perforation in leprosy. J Laryng and Otol, 1966, Lxxx, 718-732.

10 Barton RPE, Davey TF, McDOugall AC, Rees RJW, Weddell AAM. Clinical and histological studies of the nose in early lepromatous leprosy. Tenth International Leprosy Congress, Paper 6/47, Mexico City, Mexico, 1978.

11 Barton RPE. Lesions of the mouth, pharynx and larynx in lepromatous leprosy. Leprosy in India, 1974, 46, 130-134.

12 Ramu A. Central JALMA Institute for Leprosy Annual Report, 1979. Leprosy in India, 1981, 53, 307-315.

13 Kotteswaran A, Chacko CJG, Job CK. Skin adnexa in leprosy and their role in the dissemination of $M$. leprae. Leprosy in India, 1980, 52, 475-481.

14 Muir E, Chatterjee SN. The infection of stratified epithelium in leprosy. Ind J Med, 1932, 19, 1163.

15 Pedley JC. Presence of M. leprae in human milk. Lepr Rev, 1967, $38,239-242$.

16 Badger LF. Epidemiology. In Cochrane RG, Davey TF, eds. Leprosy in Theory and Practice. Bristol: John Wright, 1964.

17 Brown JAK. Factors influencing the transmission of leprosy. Trans R Soc Trop Med Hyg, 1959, 53, 179.

18 Chatterjee BR. Carrier state in leprosy. Leprosy in India, $1976,48,643-644$.

19 Figueredo N, Desai SD. Positive bacillary findings in the skin contacts of leprosy patients. Int J Leprosy, 1950, 18, 59-66.

20 MCRae DH, Shepard CC. Relationship between staining quality of M. leprae and infectivity of mice. Infect Immun, 1971, 3, 116120 .

21 Shepard CC, Levy L, Fasal P. The death of M. leprae during treatment of diphenyl diamino sulphone. Am J Trop Med Hyg, $1968,17,769-775$.

22 Dharmendra. Recent advances in microbiology in leprosy. Leprosy in India, 1977, 49, 10-35.

23 worth RM. Is it safe to treat lepromatous patients at home? A study of home exposure to leprosy in Hong Kong. Int J Leprosy, $1968,36,296-302$.

24 worth RM, Wong KO. Further notes on the incidence of leprosy in Hong Kong children living with lepromatous parents. Int J Leprosy, 1971, 39, 745-749.

25 Godal $\mathrm{T}$, Negassi $\bar{K}$. Subclinical infection in leprosy. Brit Med J, 1973, 3, 557-559.

26 Mohamed Ali P. A study of conjugal leprosy. Int J Leprosy, $1965,33,223-228$.

27 Guinto $\overline{\mathrm{S}}$. Epidemiology of leprosy. Current views, concepts and problems. In Chatterjee BR, ed. A Window on Leprosy. Wardha: 
Gandhi Memorial Leprosy Foundation, 1978, 36-52.

28 Rao PS, Karat ABA, Kalieperumal VA, Karat S. Transmission of leprosy within household. Int J Leprosy, 1975, 43, 45-54.

29 Dungal N. Is leprosy transmitted by insects? Lepr Rev, 1960, $31,25-34$.

30 Dungal N. Is leprosy transmitted by arthropods? Lepr Rev, 1961, $\underline{32}, 28-35$.

31 Narayanan L, Shankara Manja K, Kirchheimer WF, Balasubrahmanyan

M. Occurrence of M. leprae in arthropods. Lepr Rev, 1972, 43, 194-198.

32 Geater JA. The fly as potential vector in the transmission of leprosy. Lepr Rev, 1975, 46, 279-286.

33 Chandi SM, Job CK. The early cellular response to M. leprae, an ultrastructural study. Leprosy in India, 1978, 50, 345-351.

34 Leiker DL. On the mode of transmission of M. leprae. Lepr Rev, $1977,48,9-16$.

35 Job CK, Jacobson RR. Unpublished observations, 1977.

36 Nolasco JO, Lara CB. HIstological study of an early case of leprosy in a young child of leprous parents. Int J Leprosy, 1941,9 , 181-192.

37 Pddley JC. Transmission of leprosy. In Chatterjee BR, ed. A Window on Leprosy. Wardha: Gandhi Memorial Leprosy Foundation, 1978, 54-58.

38 Rees RJW, McDougall AC. Airborne infection with Mycobacterium leprae in mice. J Med Microbiol, 1977, 10, 63-68.

39 Chacko CJG. Personal communication, 1980.

40 Desikan KV, Job CK. A view of postmortem findings in 37 cases of leprosy. Int $\mathrm{J}$ Leprosy, 1968, 36, 31-44. 